\title{
Crushing and screening complex for the production of compost from organic components of municipal solid waste
}

\author{
Tavbay Khankelov ${ }^{1}$, Zokir Maksudov ${ }^{{ }^{*}}$, Nafisa Mukhamedova ${ }^{1}$ and Shavkat Tursunov ${ }^{2}$ \\ ${ }^{1}$ Tashkent State Transport University, Tashkent, Uzbekistan \\ ${ }^{2}$ Karshi Engineering Economics Institute, Karshi, Uzbekistan
}

\begin{abstract}
The existing technology for processing solid household waste (MSW) at waste transfer stations in the city of Tashkent does not allow obtaining high-quality raw materials for compost production. In this regard, a crushing and screening complex has been developed to produce compost with low energy and material consumption. The carried out theoretical and experimental studies made it possible to determine that the rotor blades should be installed along the rotor line with an angle equal to zero degrees. To overcome the resistance arising between the bottom of the crusher and the lower surface of the rotor, several holes with a diameter of $12 \mathrm{~mm}$ are drilled on the bottom of the crusher in the radial direction. It was found that the rotational speed of the electric motor of the crusher, as well as the sorting device, is $1500 \mathrm{~min}-1$, the angle of impact of organic waste on the rotor blades of the sorting device is approximately 45 degrees. The use of a crushing and screening complex made it possible to effectively grind and extract ballast inclusions from the composition of crushed organic waste by $85-90$ percent.
\end{abstract}

\section{Introduction}

Population growth, rapid urbanization, rapid economic growth, and rising living standards in developing countries have significantly accelerated the rate of quantity and quality of solid waste generation [1]. Organic components, particularly food waste, refer to the number of biological wastes, according to $[2,11,12]$ they make up about 25 to 40 percent of the total mass of the waste. According to calculations [4], the forecast of the annual volume of solid waste generation in the Republic of Uzbekistan is estimated at 14-14.5 million tons. Of these, approximately 4.5-5 million tons are organic waste, which in turn is a potential raw material for compost production.

But, one of the fundamental decisions is a separate type of waste collection and transportation system, to which most of the EU countries have switched $[5,6]$. Separate waste collection has several indisputable advantages, so with a separate method of collection and transportation, the components are pre-sorted, which eliminates the need for preparatory waste sorting. In addition, with a separate method of collection and

*Corresponding author: maksudov-55@mail.ru 
transportation, the waste components retain their original form, which favourably affects the quality of raw materials.

With mixed collection and transportation, the components of the waste, mixing with organic (food) waste, become unusable, and thus the negative impact of waste on the environment increases. Unfortunately, at present it is quite difficult to organize separate waste collection everywhere, in our opinion, the reasons for this are:

weak advertising of the separate collection of solid waste in the media, in educational institutions, as well as among residents of apartment buildings; lack of motivation to encourage them to collect separately; inadequacy of technical means, namely, machines for collecting and transporting the solid waste, stations for reloading and landfills for waste disposal; insufficient environmental education among the population, etc.

Crushing and sorting of organic components of waste is relevant for several reasons: firstly, crushed and sorted waste from ballast inclusions can serve as raw material for the production of compost; secondly, due to the crushing of organic waste, the load on specialized vehicles intended for transporting waste to landfills will significantly decrease; thirdly, the emission of harmful substances into the atmosphere will be significantly reduced. In addition, it is important to note that by reducing the volume of waste disposal, the service life of landfills increases and saves land resources used for filling waste, which in turn affects the cost of waste disposal.

Such scientists as Hongmei Lu [7], A.M. were engaged in the study of the regularities of crushing and sorting of solid household waste, as well as methods of their selection. Gonopolsky [8], N. Marashlian [9], D. Bolzonella [10], Scott W Anderson [11],

Steven P Hanson [12], Huaxun Ma, Lei Sun [13], TKXankelov [14], Sh.S. Tursunov [15], T. N. Lipatova [16], I. V. Lamzin, V.F. Zheltobryukhov, I.G. Shaikhiev [17], B.S. Kirin, A.N. Klokova [18], A.M. Musaev, R.G. Saifulin [19], Mitsuhiro Oka [20], L.N. Reutovich, M.P. Arlievsky, N.A. Averyanova [21], V.F. Reshitko, G.Yu. Zatsepina, A. A. Shashin, G. Yu. Zatsepin [22], F.B. Teshome [23].

All existing methods of mechanical waste crushing are intended mainly for homogeneous and isotropic materials. But, the creation of efficient crushers, as well as sorting devices for low energy consumption and material consumption for crushing organic waste, causes significant difficulties since waste is a conglomerate of very diverse physical and mechanical properties containing fibrous inclusions (paper, wood, leather, etc.). and fragile components (bones, stones, etc.), as well as food waste.

Also, it is relevant to develop and create a crushing and screening complex designed for crushing and sorting waste similar in physical and mechanical properties, as crushers designed for crushing all waste components are very energy-intensive, and the output product is unusable due to the presence in it in primarily harmful impurities. Consequently, these crushing and screening complexes should be subject to very stringent requirements of energy, environmental and economic nature, which are as follows: low energy and material consumption indicators; minimum percentage of ballast inclusions; simplicity of design and reliability in operation.

\section{Methods}

To study the process of crushing organic components of solid household waste, a laboratory setup was made, consisting of a hopper, a working chamber, rotating knives, side and lower grates (Figure 1). 


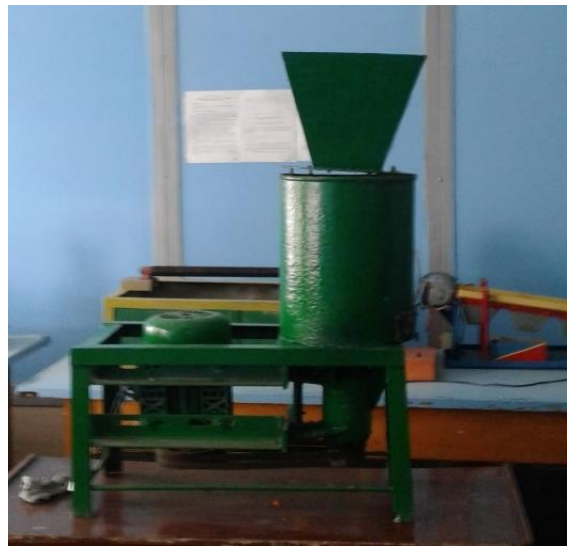

a) general view of the hammer crusher

1 is bunker; 2 is working chamber; 3 is knife rotating; 4 is hammer; 5 is rotor; 6 is side grate; 7 is lower grate; 8 is crusher frame; 9 is knife fixed; 10 is electric motor; 11 is V-belt.

Fig. 1. Hammer crusher

The hammer mill works as follows. The waste arriving for shredding falls into the loading hopper 1 . Then the waste enters the working chamber 2 , where it is accelerated to a rotation speed equal to the nominal rotation frequency of the electric motor 10 due to the creation of pressure using a hammer 4 . The accelerating waste to the nominal rotation speed of the electric motor is crushed due to impact waste by knives 9 rigidly welded to the walls of the working chamber 2 . In addition, the waste is crushed by colliding with the grate 5 . The sharpened ends of the rotating rotors 5 contribute to the effective crushing of waste.

Fibrous and film waste is crushed by rubbing between the bottom of the rotor 5 and the bottom of the working chamber 2. By erasing, the waste passes through the grate 7 located on the bottom of the working chamber.

To study the effect of the shape and size of the crusher hammer (Figure 2) and the number of knives installed on the inner wall of the crusher working chamber on the crushing efficiency, a series of preliminary experiments were carried out. Fig. 2. shows rotor-fans with different blades

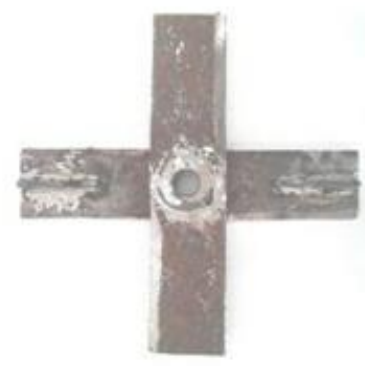

a) paraboloid hammers

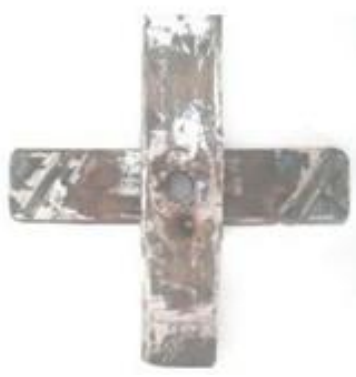

b) hammers located at an angle of 45 degrees to the rotor axis

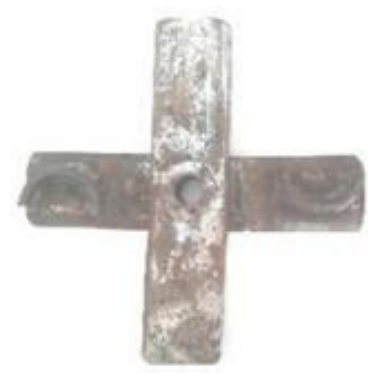

c) straight hammers located along the rotor axis

Fig. 2. Rotor designs with various hammers 
For sorting ballast inclusions from the composition of crushed municipal solid waste, a device has been developed, and a patent for an invention has been obtained [24]. The device diagram is shown in Figure 3.

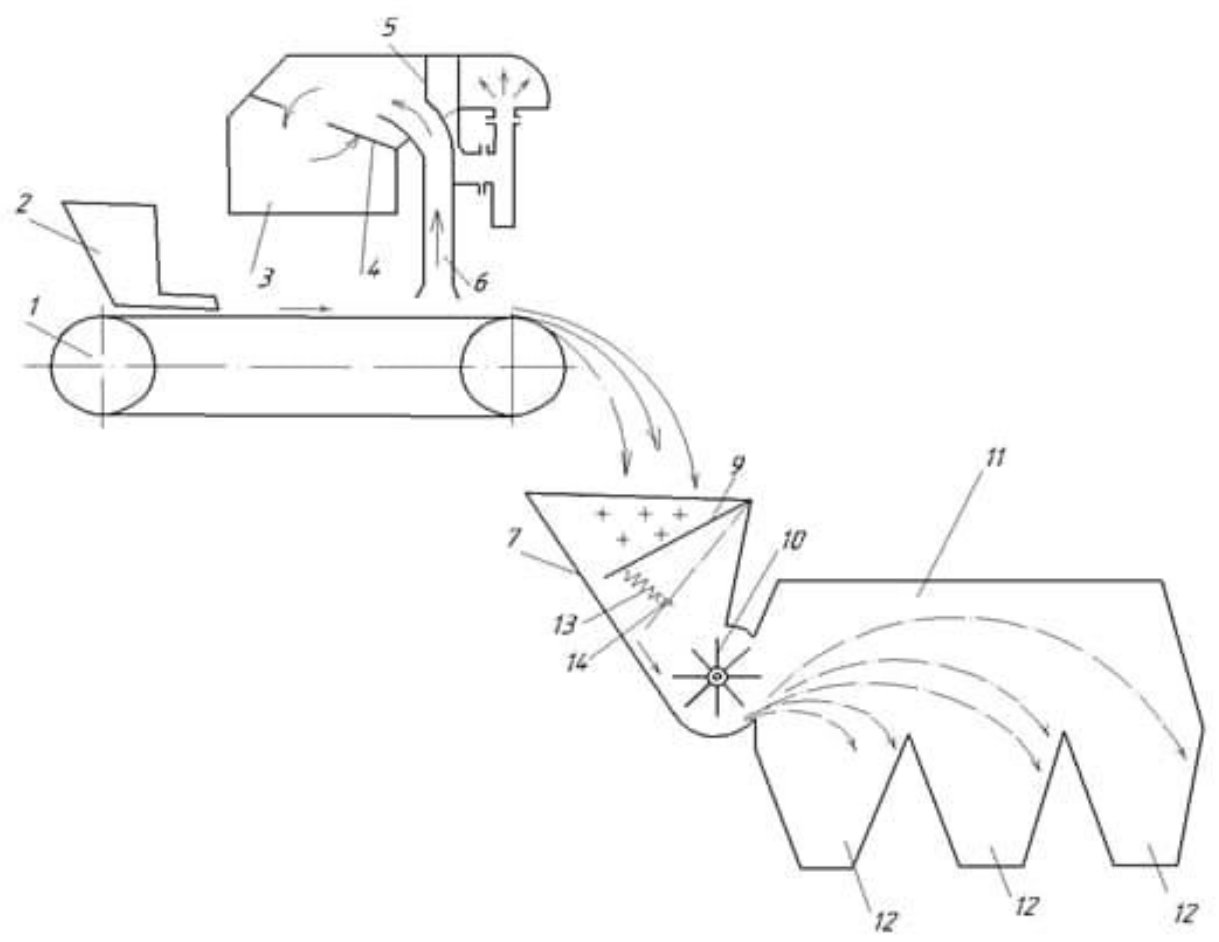

Fig. 3. Device for sorting solid household waste.

Sorting of ballast inclusions from the rest of the mass of municipal solid waste is carried out as follows.

Ballast inclusions being transported along the conveyor belt fall into the bunker 7 of the throwing device, to prevent the formation of lumps in household waste, elastic rods 8 are installed in the receiving part of the bunker, in the amount of five pieces, on the top row there are three pieces. On the bottom row two pieces are the distance between the rods equal to $120 \mathrm{~mm}$, then the loosened waste falls on the metal bar, to increase the gap between the wall and the bar, it is equipped with a compression spring.

Automatic adjustment of the gap between the metal plate and the hopper wall serves to eliminate possible clogging of the hole.

Further, the waste sliding along the base of the feed hopper in a uniform layer falls into the working area of the rotor 10 rotating at speed necessary to impart kinetic energy to its blades of heavy waste fractions. Heavier fractions fly off along a longer trajectory and fall into the distant bunker, less heavy fractions into the middle or near bunker, respectively.

\section{Results and Discussion}

To analyze the influence of operating factors on grinding and sorting waste and establish criterion dependencies, calculations were carried out based on the use of methods of the theory of similarity and dimensions using the $\pi$-theorem [25]. After making certain assumptions and restrictions, energy consumption for crushing organic components of solid 
waste in hammer crushers on the design and technological parameters can be characterized by the following functional dependence.

$$
N=F(D, n, Q, L, S, \alpha)
$$

where $N$ is the power of the crusher, Wt.; $D$ is rotor diameter, mm; $n$ is rotor speed, $s^{-1}$; $Q$ is the productivity of the crusher, $\mathrm{kg} / \mathrm{h} ; L$ is rotor length, $\mathrm{mm} ; S$ is the surface area of the hammer, $\mathrm{mm} 2$; $\alpha$ is hammer installation angle, degree. Using the method of zero dimensions with independent variables $D, n, Q$, we obtain the following criterion equation

$$
\frac{N}{D^{2} n^{2} Q}=f\left(\frac{L}{D}, \frac{S}{D^{2}}\right)
$$

In order for the two crushers to comply with similar conditions, the respective criteria must be the same. In this case

$$
P_{1}=\frac{N}{D^{2} n^{2} Q}=i d e m ; P_{2}=\frac{L}{D}=i d e m ; P_{3}=\frac{S}{D^{2}}=i d e m,
$$

Finding $\Phi$ in the general case is difficult. You can search for individual partial dependencies, for example, to determine the relationship between the power of the crusher and the diameter of the rotor.

$$
\frac{N}{D^{2} n^{2} Q}=\Phi_{1}\left(\frac{L}{D}\right)
$$

Assuming a proportional dependence in the first approximation, we have

$$
\frac{N}{D^{2} n^{2} Q}=k \frac{L}{D}
$$

where

$$
N=k D L Q n^{2}
$$

To determine the value of the coefficient $\mathrm{k}$, a series of staged experiments were carried out at the physical simulation bench of the crusher. From staged experiments, $k=7,5$.

The final form of the dependence of the crusher power on the main design and technological parameters is

$$
N=7.5 D L Q n^{2}
$$

The process of sorting municipal solid waste is expressed by the following functional relationship

$$
d=F_{1}(R, n, g, \beta, \rho)
$$

where $\mathrm{d}$ is the length of the rebound of organic components of solid waste, $\mathrm{mm} ; R$ is the radius of the rotor of the sorting device, $\mathrm{mm} ; n$ is the frequency of rotation of the rotor of the sorting device, $s^{-1} ; g$-free fall acceleration, $\mathrm{m} / \mathrm{s} 2 ; \beta$ is the angle of rebound of waste constituents, degree; $\rho$ is the density of MSW constituents, $\mathrm{kg} / \mathrm{m} 3$.

Using the method of zero dimensions with independent variables $R, n, \rho$, we obtain the following criterion equation

$$
\frac{d}{R}=f_{1}\left(\frac{g}{R n^{2}}, \beta\right)
$$




$$
\mathrm{P}_{1}=f_{1}\left(\mathrm{P}_{2}^{-1}, \mathrm{P}_{3}\right)
$$

where: $P_{1}=\frac{d}{R}, P_{2}=\frac{g}{R n^{2}}, P_{3}=\beta$

In order for two sorting devices to comply with similar conditions, the corresponding criteria must have the same values. In this case

$$
\frac{d}{R}=i d e m, \frac{g}{R n^{2}}=i d e m, \beta=i d e m
$$

Let us construct the dependence on the plane $P_{1}=f_{2}\left(P_{2}^{-1}\right)$ with parameter $P_{3}$.

Figure 4. presented dependence $P_{1}$ from $P_{2}^{-1}$ with parameter $\mathrm{P}_{3}$.

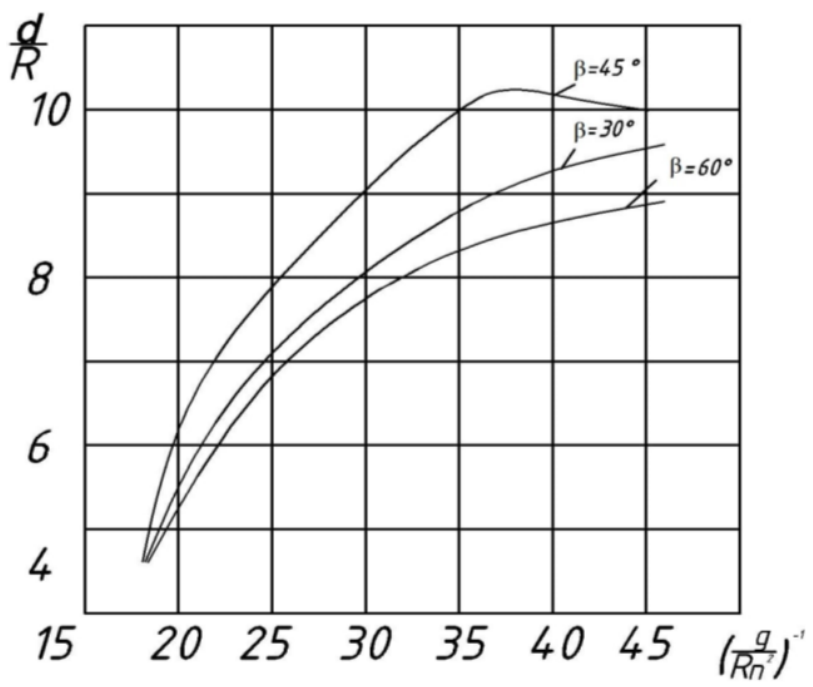

Fig. 4. Relationship between parameters in dimensionless coordinates.

Based on the plotted graphs in dimensionless coordinates, it is possible to determine the boundaries of the region of optimal parameters, within which it is possible in a first approximation, to select the parameters of the sorting unit and explain some particular dependencies. High values $\frac{d}{R}$ at the same values of the complex of quantities $\left(\frac{g}{R n^{2}}\right)^{-1}$ obtained due to an impact angle of approximately 45 degrees.

\section{Conclusions}

1. Due to minor changes, in particular, due to the drilling of holes on the bottom of the crusher, a hammer crusher design with low energy and material consumption was created.

2. The following main parameters of the crusher have been determined: $n=$ $1500 \frac{\mathrm{ob}}{\min } ; \alpha=0^{0} ; D=270 \mathrm{~mm} ; \mathrm{L}=100 \mathrm{~mm} ; \mathrm{S}=2400 \mathrm{~mm} 2$.

3. The developed design of the sorting device allows to supply crushed organic waste to the rotor blade in a uniform layer, which significantly increases the efficiency of sorting.

4. The following main parameters of the crusher have been determined: $n=$ $1500 \frac{\mathrm{ob}}{\min } ; \beta=45^{0} ; R=500 \mathrm{~mm} ; d=2500-3000 \mathrm{~mm}$. 


\section{References}

1. Khankelov T., Askarhodzhaev T., Mukhamedova N. Determination of key parametres of devise for sorting municipal solid waste. (Journal of Critical Reviews. 7,(4), pp. 2728.(2020)

2. Khankelov T., Tursunov Sh., Maksudov Z. Domestic Solid Waste Crusher. International Journal of Psychological Rehabililation, 24, (07), pp.8090-8091. (2020)

3. Adylova M. The problem of primary sorting of waste. (Publishing house "Fan" of the Academy of Sciences of the Republic of Uzbekistan). 8. pp.10-14. (2006)

4. Resolution of the President of the Republic of Uzbekistan. On approval of the Strategy for solid waste management in the Republic of Uzbekistan for the period 2019-2028. (Tashkent). p. 59. (2019)

5. Ulanova O.V., Salkhofer S.P., Vyunsch K. Integrated waste management device. (Housing and communal services, Textbook. Moscow: Publishing house of the Academy of Natural Sciences).p .520. (2016)

6. Petrukov O.P., Shubov L.Ya., Gaev F.F. Strategy and tactics for solving the problem of municipal solid waste in the Moscow region. (Scientific and technical aspects of environmental protection. VINITI), 1. p. 123 p. (2008).

7. Hongmei Lu., Roman Sidortsov. Sorting a problem: A co-production approach to household waste management in Shanghai, China. (Waste Management) (95), pp.271277. (2019)

8. Gonopolskiy A.M., Zinyakina E.V., Denisova T.V. Waste cutter roller. (Bulletin of SUSU. Series "Food and Biotechnology". (5). (1), pp.45-54. (2017)

9. Marashlian N. Effect of food waste and wastewater management. (Waste Management \& Research). 23(1), pp.20-31. (2005)

10. Bolzonella D. The under-sink garbage grinder: a friendly technology for the environment. (Environmental Technologe). 24, (3), pp.349-359. (2003).

11. Scott W Anderson, Steven P Hanson, Joseph G Farmerie, James R Patterson. Food waste disposer shredder assembly: pat. 7360729. (United States Emerson Electric Co. Appl. 10/908,056), p. 12. (2008)

12. Steven P Hanson. 2011 Water recycling food waste disposer system: pat. US7963469 (United States Emerson Electric Co. Appl. 12/028,855) p.15. (2011)

13. Huaxun Ma, Lei Sun. 2013 Grinding disk for food waste disposer: pat. US20130277475 A1 (United States Zhang Zhou Sunwise Environmental Protection Co. Appl. No.: US 13/880), 1656 p.

14. Khankelov, T.K. A theory of sorting solid domestic waste. (Stroitelnye Dorozhnye Mashiny) (5). pp.34-36. (2001)

15. Tursunov, Sh.S. Analysis of existing designs of crushers for crushing municipal solid waste. International Journal for Innovative Engineering and Management Research., (01), pp. 274-276. (2021).

16. Lipatova T.N. The culture of sorting solid household waste in large cities. (Annotation of reports of materials of the international scientific-practical conference dedicated to the 100th anniversary of academician P.A. Kirpichnikov). pp. 240-242. (2013)

17. Lamzina I.V., Zheltobryukhov V.F., Shaikhiev I.G. Analysis of methods for sorting solid household waste. (Bulletin of Kazan Technological University), 5, pp. 244-245. (2015)

18. Kirin B.S., Klokova A.N. 2014 Modern technologies for the separation of plastics waste. (Advances in chemistry and chemical technology. Volume XXVIII). 3. pp.3133. (2014)

19. Musaev A.M., Saifulin R.G. Method of vibro-pulsation sorting of solid household waste. (Izvestia KazGASU Ecology in construction). 1, pp. 141-145. (2021) 
20. Mitsuhiro Oka. Sorting apparatus in solid waste sorting system. pat.US0055464100A (United States: Okasan Corparation. Co Appl. №139118) p. 10. (1993)

21. Reutovich L.N., Arlievsky M.P., Averyanova N.A. Method for cleaning compost from solid domestic waste of ballast fractions: patent application. 2004104371 (Russian Federation: MPKV9/00/:LLC "GIPROKHIM-TECHNOLOG") p.11. (2004).

22. Reshitko V.F., Zatsepina G.Yu., Shanin A.A., Maslov V.S., Krelman E.B. Method of cleaning and processing solid household waste and a complex for its implementation. patent application 2000130971/13 (Russian Federation: MPKV09V3/13) p 12. (2000).

23. Teshome F.B. 2021 Municipal solid waste management in Ethiopia; the gaps and ways for improvement. (Journal of Material Cycles and Waste Management, (23), pp.18-31. (2021).

24. Khankelov T.K., Mukhamedova N.B. Device for sorting solid household waste. (Patent application: IAP2018.0232). (2018).

25. V. I. Balovnev, Optimization and selection of innovative systems and processes of transport and technological machines: Textbook. (Moscow TEKHPOLIGRAFTSENTR) p. 392. (2014) 